\title{
Obesity leads to underestimation of ventricular volumes and abnormal myocardial strain in repaired Tetralogy of Fallot as measured by cardiac MRI
}

\author{
Scott A Simpson", Suzanne L Field, Neeru Kaushik, David Parra, Jonathan H Soslow \\ From 17th Annual SCMR Scientific Sessions \\ New Orleans, LA, USA. 16-19 January 2014
}

\section{Background}

Obesity is an increasing epidemic that has not spared children and adults with congenital heart disease. Patients with repaired tetralogy of Fallot with trans-annular patch (rTOF-TAP) have significant pulmonary insufficiency and right ventricular (RV) enlargement. Recommendations for pulmonary valve replacement (PVR) include body surface area (BSA)-indexed RV end diastolic volume (RVEDVi) $>150 \mathrm{ml} / \mathrm{m} 2$ or indexed RV end systolic volume (RVESVi) $>80 \mathrm{ml} / \mathrm{m} 2$, estimated by cardiac MRI (CMR). We hypothesized that: 1) overweight and obese patients with rTOF-TAP have underestimated indexed ventricular volumes when compared to volumes indexed to ideal BSA and 2) these patients have altered parameters of cardiac function compared to weight appropriate patients.

\section{Methods}

Retrospective review of 86 patients from 2009-2013 with rTOF-TAP who underwent CMR. Mean age 20.1 years ( \pm 10.9). Patients assigned weight categories by Center for Disease Control guidelines for children and adults based on body mass index (BMI): appropriate weight $(\mathrm{n}=51)$, overweight $(\mathrm{n}=23)$, and obese $(\mathrm{n}=12)$. CMR analysis included: 1) RV volumes and RV ejection fraction (RVEF); 2) Left ventricular (LV) volumes and LVEF; 3) Peak circumferential LV strain $\left(\varepsilon_{\mathrm{cc}}\right)$ using HARP analysis of myocardial tagged images. Overweight and obese patients assigned ideal BSAs to recalculate indexed RV volumes. Mann-Whitney U was used to compare continuous variables between groups.

Vanderbilt University Medical Center, Nashville, Tennessee, USA

\section{Results}

Mean BMI in appropriate weight $19.8 \mathrm{~kg} / \mathrm{m} 2$, overweight $26.4 \mathrm{~kg} / \mathrm{m} 2$, obese $33.5 \mathrm{~kg} / \mathrm{m} 2$. Obese and overweight patients had significantly larger absolute RVEDV and LVEDV compared to weight appropriate patients (RV mean $234 \mathrm{ml}$ vs. $200 \mathrm{ml}, \mathrm{p}=0.014$; LV mean $113 \mathrm{ml}$ vs. $92 \mathrm{ml}, \mathrm{p}=0.002$ ). No significant difference in RVEF and LVEF among groups. When RV volumes were corrected for ideal BSA, 11 (31\%) additional overweight and obese patients met standard criteria for PVR referral (Figure 1); mean change RVEDVi $22.9 \mathrm{ml} / \mathrm{m} 2$ (range 4.8-62 ml/m2), mean change RVESVi $11.3 \mathrm{ml} / \mathrm{m} 2$ (range $2.9-38.4 \mathrm{ml} / \mathrm{m} 2$ ). There was a statistically significant difference between $\varepsilon_{\mathrm{cc}}$ in appropriate weight $(-17.3 \%)$ and obese $(-14.3 \%)$ patients, $(-2.94 \%, 95 \% \mathrm{CI}\{-5.2,-0.6\} \mathrm{p}=0.007)$ (Figure 2); segmental analysis between appropriate weight and obese patients demonstrated decreased $\varepsilon_{\mathrm{cc}}$ in anteroseptal, inferior, and inferolateral segments $(\mathrm{p}<0.001, \mathrm{p}=0.003, \mathrm{p}=0.016$, respectively). No significant differences in $\varepsilon_{\mathrm{cc}}$ noted between appropriate weight and overweight patients.

\section{Conclusions}

Increased BMI leads to the underestimation of indexed RV volumes, possibly affecting timing of PVR. This underestimation should be corrected using ideal BSA. Decreased $\mathrm{LV} \varepsilon_{\mathrm{cc}}$ has not been previously reported in obese patients with rTOF-TAP. Although clinical implications of abnormal $\varepsilon_{\mathrm{cc}}$ are unclear, these patients may be at higher risk for early LV dysfunction. Further studies on $\varepsilon_{\mathrm{cc}}$ in this patient population are recommended.

\section{Funding}

Funded in part by NIH T32HL 105334. 


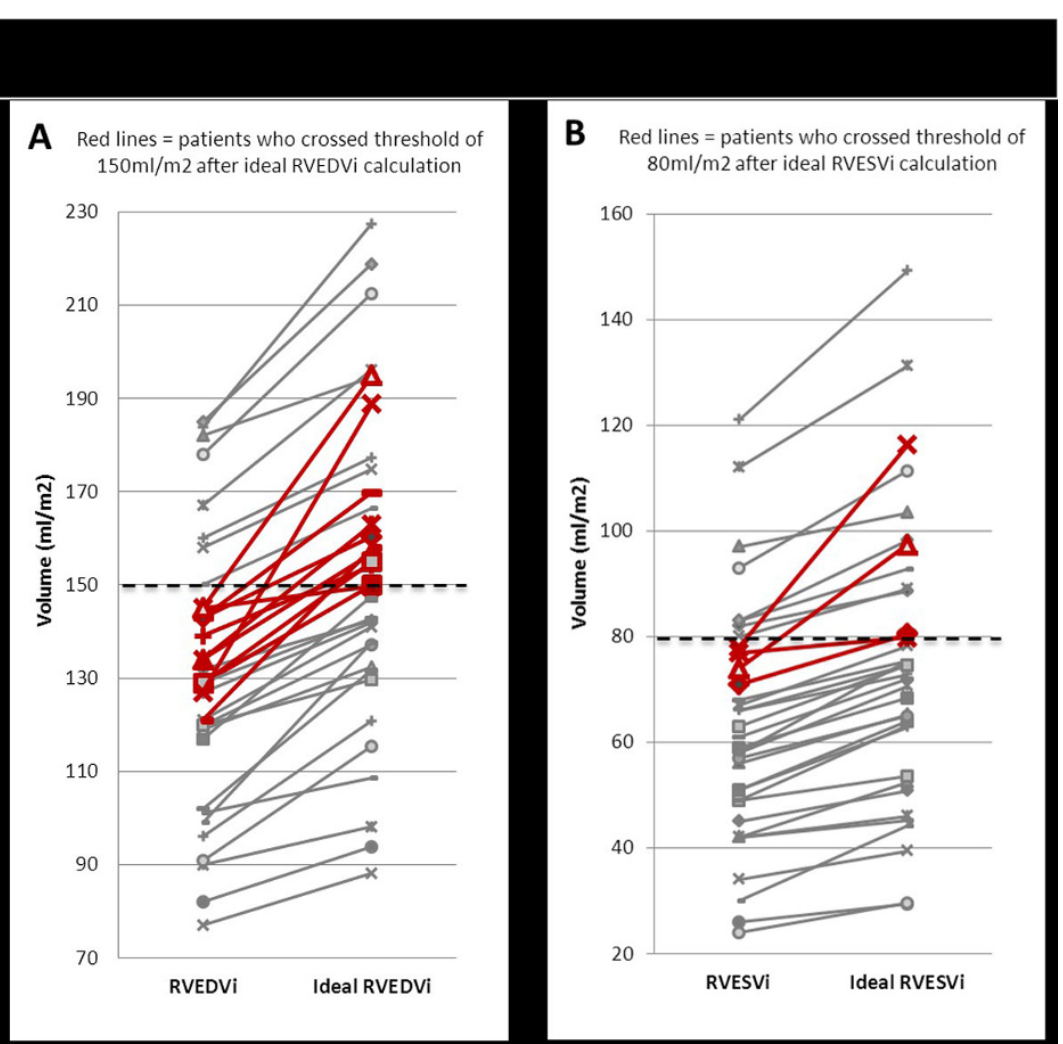

Figure 1

\section{Figure 2: Peak Global Circumferential LV Strain in rTOF-TAP}

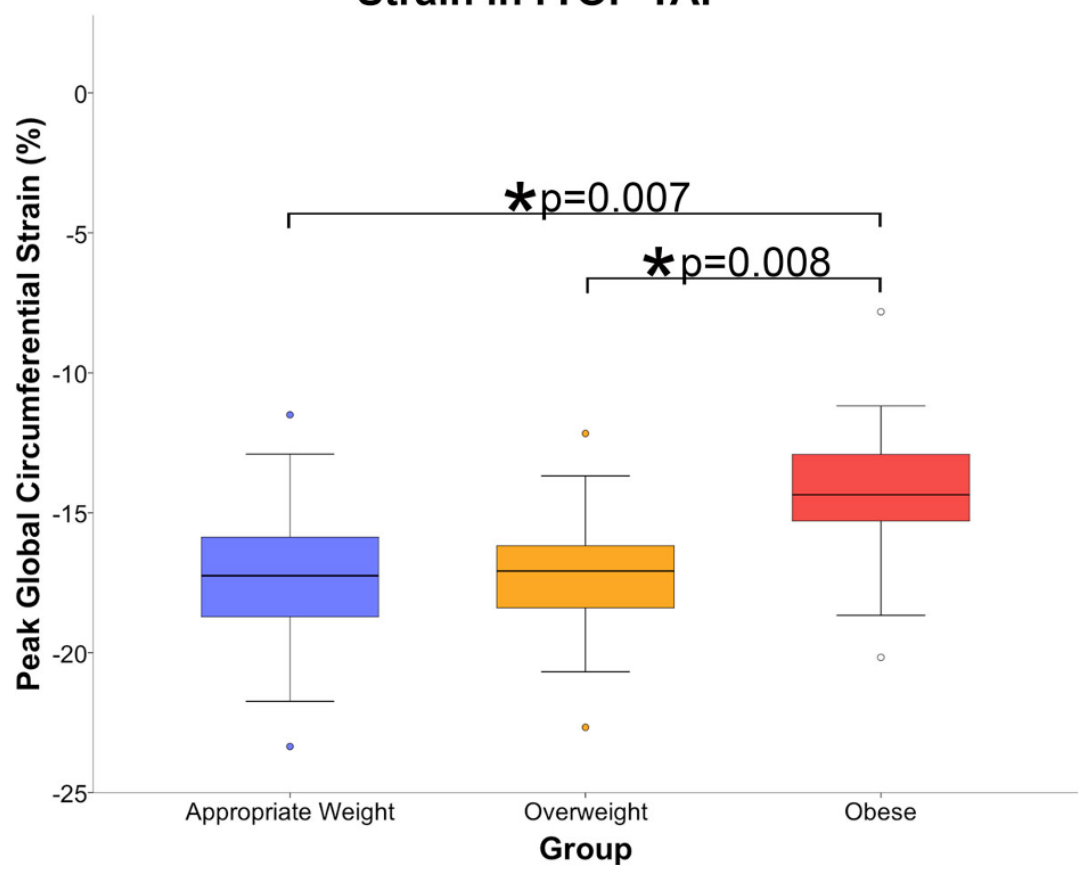

Figure 2 Peak global cicumferential LV strain in rTOF-TAP 
doi:10.1186/1532-429X-16-S1-P112

Cite this article as: Simpson et al:: Obesity leads to underestimation of ventricular volumes and abnormal myocardial strain in repaired

Tetralogy of Fallot as measured by cardiac MRI. Journal of Cardiovascular Magnetic Resonance 2014 16(Suppl 1):P112.

Submit your next manuscript to BioMed Central and take full advantage of:

- Convenient online submission

- Thorough peer review

- No space constraints or color figure charges

- Immediate publication on acceptance

- Inclusion in PubMed, CAS, Scopus and Google Scholar

- Research which is freely available for redistribution

Submit your manuscript at www.biomedcentral.com/submit 